\title{
Urdimento
}

Revista de Estudos em Artes Cênicas

E-ISSN: 2358.6958

\section{O estado da nossa união: prisão, política e performance dentro de uma democracia frágil}

Marena Dieden, Caroline Henderson, Ashley Munger, Steven Nicholson, Tyrone Reyes, Richard Strong, Raschid Zimmerman

\section{Para citar este artigo:}

DIEDEN, Marena; HENDERSON, Caroline; MUNGER, Ashley; NICHOLSON, Steven; REYES, Tyrone; STRONG, Richard; ZIMMERMAN, Raschid. O estado da nossa união: prisão, política e performance dentro de uma democracia frágil. Urdimento, Florianópolis, v. 3, n. 39, nov./dez. 2020.

DOI: http:/dx.doi.org/10.5965/14145731033920200106 

O estado da nossa união: prisão, política e atuação dentro de uma democracia
frágil

\author{
Marena Dieden', Caroline Henderson², Ashley Munger ${ }^{3}$, \\ Steven Nicholson ${ }^{4}$, Tyrone Reyes ${ }^{5}$, Richard Strong ${ }^{6}$, Raschid Zimmerman ${ }^{7}$
}

\author{
Tradução de Conrado Mari
}

\begin{abstract}
${ }^{1}$ Aluna do primeiro ano de Direito na University of California School of Law. Em maio de 2019, ela recebeu seu Bacharelado em Políticas Públicas pela Escola Gerald R. Ford de Políticas Públicas da Universidade de Michigan. Durante seu tempo na Universidade de Michigan, Marena foi voluntária no Prison Creative Arts Project por três anos e meio, facilitando oficinas de escrita criativa em Vista Maria, um programa residencial para jovens ordenado pelo tribunal, e em Cotton Correctional Facility, uma prisão estadual masculina. marenadieden@gmail.com
\end{abstract}

${ }^{2}$ Assistente social mestre licenciada que fornece serviços de saúde mental e defesa para aqueles afetados pelos sistemas legais criminais. Em maio de 2018, ela obteve seu diploma de Mestre em Serviço Social pela Universidade de Michigan, onde se ofereceu e concluiu um estágio de campo no Prison Creative Arts Project. Antes de se mudar para Michigan para fazer pós-graduação, Caroline trabalhou em uma organização sem fins lucrativos de desenvolvimento de jovens na cidade de Nova York de 2014 a 2016. Caroline se formou na Universidade de Columbia em 2014, com bacharelado conjunto em Estudos de Direitos Humanos e Literatura Inglesa. carhen@umich.edu ashleymunger12@gmail.com

${ }^{3}$ É de White Lake, Michigan. Ela freqüentou a University of Michigan (2019) para seus estudos de graduação e a Boston University para seu mestrado em educação. É professora de escola pública e espera cursar direito para se tornar advogada de defesa criminal. anmunger@umich.edu

${ }^{4}$ Steven Nicholson nasceu em 14 de maio de 1983. Ele é dos projetos Herman Gardens* em Detroit. Ele tem educação universitária incompleta no Henry Ford Community College em Dearborn, Michigan. Ele ama Jesus, mas teve uma infância pobre com opções muito limitadas de sucesso na vida, então acabou fazendo escolhas muito ruins que causaram um acidente horrivel e levaram ao seu encarceramento. Ele se sente completamente responsável por sua situação atual. O Prison Creative Arts Project (PCAP) ajudou-o a assumir a responsabilidade pelas suas ações. PCAP é realmente uma lufada de ar fresco que Nicholson sugere que todos neste mundo deveriam experimentar (ou algo parecido). Os alunos e diretores do PCAP são uma dádiva de Deus e Nicholson é sempre grato por eles. Obrigada, Jesus! Aleluia! Ele espera que todos os leitores gostem deste artigo. (*Os projetos são instalações de habitação pública).

${ }^{5}$ Membro do Prison Creative Arts Project desde 2016 e da National Lifers Association (uma organização de liderança para pessoas em prisão perpétua) desde 2013.

${ }^{6}$ Vice-presidente da National Lifers of America, capítulo \# 1024, desde 2014. Ele participa do Prison Creative Arts Project desde 2016. Em 2020, Strong recebeu um diploma em artes liberais pelo Jackson College, onde é também um Senior Writing Fellow e membro da sociedade de honra Phi Theta Kappa. Ele fez parte da Lista do reitor * de 2016-2020. Ele foi assistente de ensino do curso de Sociologia e Justiça Criminal da Universidade de Albion em 2016 e Tutor de Preparação de Emprego desde 2019. De 2017-2020, ele também atuou como mentor do Departamento de Psicologia Penitenciária do Departamento de Michigan para homens encarcerados com problemas de adaptação. Ele trabalhou como tutor para homens que conquistaram o grau de equivalência geral ** de 2013-2017. (*estar na lista do reitor é uma forma de homenagear o alto desempenho acadêmico; ** Um grau de equivalência geral é um diploma de segundo grau obtido por pessoas que não concluíram o segundo grau em um ambiente normal).

${ }^{7}$ Membro do Prison Creative Arts Project desde 2016.

8 Tradução do inglês realizada por Conrado Mari que nasceu em São Paulo, Brasil e se mudou para Michigan, Estados Unidos ainda adolescente. Ele estudou na Eastern Michigan University, onde obteve um B.S. em Gestão Hospitalar. cmari@emich.edu 


\title{
Resumo
}

De setembro a dezembro de 2017, quatro alunos da Universidade de Michigan treinados pelo Prison Creative Arts Project facilitaram um workshop de redação criativa na G. Ronald Cotton Correctional Facility em Jackson, Michigan, EUA. Doze homens encarcerados juntaram-se aos quatro alunos facilitadores para reuniões semanais de workshops que culminaram em uma apresentação de escrita criativa original. Este artigo descreve a estrutura do workshop e o treinamento fornecido pelo Prison Creative Arts Project, apresenta os indivíduos que participam deste workshop de redação criativa do outono de 2017 e descreve como seus processos criativos evoluíram para incluir discurso político e crítica. O artigo demonstra como a escrita criativa e o teatro fornecem à população encarcerada a oportunidade única de expressar plenamente as opiniões e atitudes políticas dentro dos muros da prisão e destaca paralelos entre os eventos atuais e a política de 2017 e os de 2020. Para completar este artigo, os alunos facilitadores escreveram uma carta descrevendo o projeto e pedindo interesse em coautoria e a enviaram aos participantes encarcerados. Os alunos facilitadores compilaram um questionário e o enviaram aos participantes encarcerados que estavam interessados em ser coautores do artigo. Os coautores ainda residentes na prisão continuaram a se corresponder com aqueles que viviam fora da prisão via correio, produzindo seções do artigo e fornecendo redação original do workshop de 2017.

Palavras-chaves: Escrita criativa. Encarceramento. Prisão. Política. Performance.

The state of our union: prison, politics, and performance within a fragile democracy

\begin{abstract}
From September to December of 2017, four University of Michigan students trained by the Prison Creative Arts Project facilitated a creative writing workshop at G. Ronald Cotton Correctional Facility in Jackson, Michigan, USA. Twelve incarcerated men joined the four student facilitators for weekly workshop meetings which culminated in a performance of original creative writing. This article describes the workshop framework and training provided by the Prison Creative Arts Project, introduces the individuals participating in this particular, fall 2017 creative writing workshop, and describes how their creative processes evolved to include political discourse and critique. In conclusion, the article demonstrates how creative writing and theater provide the incarcerated population with the unique opportunity to fully express political opinions and attitudes within prison walls, and highlights parallels between the current events and politics of 2017 and those of 2020. In order to complete this article, the student facilitators wrote a letter describing the project and asking for interest in co-authorship and mailed it to the incarcerated participants. The student facilitators then compiled a questionnaire and mailed it to the incarcerated participants who were interested in co-authoring the article. The co-authors still residing in prison continued to correspond to those living outside of prison via mail, producing sections of the article and providing original writing from the 2017 workshop.
\end{abstract}

Keywords: Creative writing. Incarceration. Prison. Politics. Performance. 
El estado de nuestra unión: prisión, política y actuación en una democracia frágil

\section{Resumen}

De septiembre a diciembre de 2017, cuatro estudiantes de la Universidad de Michigan capacitados por Prison Creative Arts Project facilitaron un taller de escritura creativa en el Centro Correccional G. Ronald Cotton en Jackson, Michigan, EE. UU. Doce hombres encarcelados se unieron a los cuatro facilitadores estudiantiles para las reuniones semanales del taller que culminaron con una presentación de escritura creativa original. Este artículo describe el marco del taller y la capacitación brindada por Prison Creative Arts Project, presenta a las personas que participan en este taller de escritura creativa en particular, otoño de 2017, y describe cómo evolucionaron sus procesos creativos para incluir el discurso político y la crítica. El artículo demuestra cómo la escritura creativa y el teatro brindan a la población encarcelada la oportunidad única de expresar plenamente sus opiniones y actitudes políticas dentro de los muros de la prisión, y destaca los paralelismos entre los acontecimientos actuales y la política de 2017 y los de 2020. Para completar En este artículo, los estudiantes facilitadores escribieron una carta describiendo el proyecto y pidiendo interés en la coautoría y la enviaron por correo a los participantes encarcelados. Los estudiantes facilitadores luego compilaron un cuestionario y lo enviaron por correo a los participantes encarcelados que estaban interesados en ser coautores del artículo. Los coautores que aún residen en prisión continuaron correspondiendo a los que viven fuera de la prisión por correo, produciendo secciones del artículo y proporcionando escritos originales del taller de 2017.

Palabras clave: Escritura creativa. Encarcelamiento. Prisión. Política. Performance. 


\section{Introdução}

"Me leve até a Florida"

O taxista se virou, com uma mão atrás do apoio de cabeça do assento de passageiro. O que, rapaz? Isso aqui é um taxi de Nova lorque, você está ficando louco?

Um segundo passageiro se intrometeu. "Olha, eu tenho dinheiro. Aqui está frio demais; eu não suporto Nova Iorque em novembro. Vamos embora."

"Você está maluco. Eu tenho uma família esperando por mim esta noite. Fora do meu taxi."

"Vai valer a pena! Vamos cara, seja mais aventureiro! Você vai ficar nessa mesma cidade, dirigindo esse taxi para sempre e nunca sair daqui?

O motorista encostou o carro. "Eu não sou obrigado a aceitar desaforos no meu próprio taxi. Eu não vou mais te levar a lugar nenhum." Com isso, o motorista tirou as chaves, bateu a sua porta, e retornou ao seu assento na amolgação de mesas dobráveis, puxadas uma do lado da outra, no outro lado da sala.

Claro, nós não estávamos nas ruas de Nova lorque, e definitivamente não estávamos na Florida. Não estávamos perto de taxi algum. Era inverno e éramos um grupo de adultos agregados na G. Ronald Cotton Correctional Facility, uma prisão estadual em Jackson, no estado de Michigan, improvisando um jogo teatral em um carro invisível que era na verdade apenas quatro cadeiras de plástico alinhadas em duas fileiras. Além do nosso táxi, a sala tinha várias mesas dobráveis estilo anos 1980 - do tipo com grandes folhas de adesivos no topo imitando madeira - e mais algumas cadeiras de plástico, postas ao redor das mesas como se estivessem prontas para um jantar em família. Um quadro-negro empoeirado, janelas reforçadas com telas de arame e algumas frases motivacionais espalhadas em folhas de papel envelhecidas adornavam as paredes.

Todos nós, doze participantes encarcerados e quatro facilitadores universitários, havíamos sido reunidos como escritores ou aspirantes a escritores. 
Nos reuníamos uma vez por semana nas noites de quinta-feira, para um workshop (Oficina) de escrita criativa com duração de um semestre. Por isso nós já esperávamos. O que não planejamos foi que, quando estivéssemos juntos, seria também para confraternização, política e atuação.

Neste artigo, três facilitadores não-encarcerados e quatro participantes ainda presos se reúnem novamente para refletir sobre o poder do que criamos. Escrevemos e colaboramos neste artigo correspondendo-nos pelo correio. Nas cartas que nos correspondemos nos últimos meses, lembramos a expectativa e a incerteza que sentimos na preparação para nosso primeiro workshop, como as perspectivas políticas começaram a surgir em nossos textos desde o primeiro workshop, como continuamos a usá-los para fundamentar a nós mesmos e nosso propósito na escrita, e como nossa orientação coletiva em política e justiça social culminou em uma mistura produtiva de teatro e poesia que nenhum de nós jamais esquecerá. Essas coisas são discutidas aqui em uma ordem cronológica solta. Embora em grande parte tenhamos entrado no workshop com a expectativa de uma experiência pessoal e educacional, argumentamos hoje que, para nós, é difícil separar a arte ou a educação do indivíduo do contexto político em que elas ocorrem. Nosso tempo juntos nos ajudou a usar a escrita criativa para processar e expressar nossos sentimentos sobre o momento político tenso que estávamos vivenciando no outono de 2017 - uma época que nos pareceu que as coisas que sabíamos sobre democracia, como a verdade e a justiça, estavam sendo abaladas e ameaçadas. A estrutura do nosso workshop nos permitiu recorrer a elementos do teatro para comunicar esses sentimentos aos outros, criando uma forma de solidariedade mesmo no contexto da prisão - um ambiente altamente vigiado e restrito. Enquanto escrevemos agora, estamos vivendo um momento político mais tenso do que poderíamos ter imaginado três anos atrás, quando nosso Workshop terminou. Nossas cartas nos últimos meses e este artigo - o produto dessas cartas - são, além de uma forma de nos reconectarmos enquanto vivemos a dolorosa era do COVID-19, a contínua destruição causada pela supremacia branca e a administração de Trump, um lembrete das maneiras pelas quais a arte - em todas as suas formas - pode servir como uma ferramenta política. A apresentação que 
escrevemos, dirigimos e executamos foi uma declaração política coletiva que se valeu da força de nossa solidariedade e comunhão para criticar as estruturas de poder que prendem todos nós - os presos e os livres.

\section{O PCAP no Presídio e as Origens do Workshop de Escrita Criativa em Outono de 2017}

No outono de 2017, quatro facilitadores se reuniram de diferentes cantos da Universidade de Michigan em Ann Arbor. Cada facilitador descobriu o Prison Creative Arts Project - PCAP (Projeto de Artes Criativas no Presídio), uma organização da universidade que leva uma programação de arte para as prisões estaduais e divulga as obras artísticas, de diferentes linguagens, criada por pessoas que vivenciam o encarceramento.

O PCAP organiza cerca de uma dúzia de workshops em escrita criativa, teatro, artes visuais e música em prisões e instituições para jovens a cada semestre, além de habilitar alunos da universidade a se tornarem facilitadores e colaboradores neste programa. Quatro alunos (Marena Dieden, Caroline Henderson, Ashley Munger e Bryce Vandenbelt) se inscreveram para ir para a mesma prisão, uma vez por semana, por doze semanas e por acaso, acabaram como co-facilitadores.

Apesar de praticamente não se conhecerem anteriormente, os quatro facilitadores começaram o semestre com a expectativa de uma experiência profundamente pessoal. Cada facilitador ouviu histórias ou participou de workshops anteriores do PCAP, criando espaços de reflexão pessoal para participantes e facilitadores, e cada um estava ciente do poder da escrita criativa para promover abertura a vulnerabilidade e introspecção. Na noite daquele primeiro workshop, as apostas pareciam altas; os facilitadores estavam preocupados em criar a experiência pessoal e educacional desejada para todos os envolvidos, especialmente no contexto do início deste Workshop, pois eram um grupo de estranhos em um sistema penal em que a impessoalidade é a norma. Ainda assim, sentíamos muita confiança. Aqui, a facilitadora do workshop Ashley Munger reflete sobre o período antes do workshop iniciar: 
"Eu participava do PCAP desde janeiro de 2017 como membro do "Literature Review Board" (Conselho Administrativo de Revisão/Análise da Literatura), o órgão que seleciona textos submetidos por homens e mulheres encarceradas em todo o estado de Michigan e os compila em um jornal literário anual, o Michigan Review of Prisoner Creative Writing (Revisāo/Análise da Escrita Criativa de Prisioneiros em Michigan). Naquela época, eu tinha acabado de conhecer Marena por meio de uma organização da Universidade de Michigan para estudantes interessados em Direito. A amizade entre Marena e eu veio rápido; partilhamos uma visão de mundo semelhante e nos uníamos em torno de tópicos sobre política, direito e justiça. Foi Marena que me informou que a Dra. Ashley Lucas, na época diretora do PCAP, dava cursos sobre tópicos de encarceramento na Universidade de Michigan e, juntas, Marena e eu nos inscrevemos para fazer o curso Atonement Project (Projeto de Reparação) com Ashley Lucas e a instrutora de música Kathy Kelly. Para sermos aceitos no curso, tivemos que sentar-nos com os dois instrutores e garantir a eles que sabíamos a responsabilidade que estávamos assumindo. Todos no curso deveriam ministrar um workshop dentro de uma prisão, em conjunto com reuniões duas vezes por semana para discutir literatura sobre temas relacionados à intersecção dos espaços artísticos e carcerários.

Fomos a Cotton pela primeira vez para uma orientação sobre a prisão, que foi conduzida por funcionários da carceragem. Eles nos disseram para nunca virar as costas para nenhum participante do workshop ou ficarmos sentados enquanto algum deles estivesse de pé, pois esses eram sinais de submissão. Eles nos disseram que não deveríamos nos preocupar em usar maquiagem, porque "não há ninguém aqui para impressionar mesmo." Tudo isso fez com que os participantes do workshop parecessem caricaturas de homens temíveis. Apesar disso, meu treinamento como facilitadora com o PCAP me deixou mais cautelosa com os oficiais correcionais do que com qualquer pessoa. No treinamento, fomos instruídos a não usar o sutiã errado, não usar roupas muito apertadas ou muito largas, falar com os guardas com respeito e não chamar os participantes pelo nome na frente dos guardas." 


\section{Primeiro Workshop}

Conforme a data de início do workshop se aproximava, os quatro facilitadores se reuniram para discutir o planejamento e as metas para o semestre. A agenda do primeiro workshop incluiu um tempo designado para estabelecer as diretrizes e expectativas do grupo. Era importante para os facilitadores que o estabelecimento de diretrizes para a workshop fosse uma tarefa colaborativa entre facilitadores e participantes, principalmente porque as pessoas encarceradas frequentemente carecem de poder sobre seu ambiente cotidiano e as regras dos espaços que habitam regularmente. Era importante que o workshop se estabelecesse como uma comunidade de indivíduos, com o objetivo de compartilhar um espaço criativo e empoderador que valoriza todos os artistas por suas contribuições únicas. A lista de diretrizes coletivas estabelecida no primeiro workshop incluiu: 1) Respeite a opinião de todos, 2) Leve a opinião de todos a sério, 3) Não julgue, e apoie a criatividade de todos, 4) "Passe o microfone" - Em outras palavras, esteja ciente das limitações de tempo, dê tempo e espaço para todos participarem e compartilharem, 5) Manter o que os outros compartilham no workshop em sigilo e 6) Buscar sempre o crescimento em arte e no conhecimento.

Outra tarefa importante do primeiro dia foram as apresentações. O PCAP fornece vários exemplos de atividades introdutórias, com o objetivo de estabelecer relacionamento entre os participantes e facilitadores, aprendendo os nomes de cada um e conhecendo um pouco sobre cada indivíduo. Nomes são um assunto interessante na prisão, porque todos os funcionários da prisão e pessoas encarceradas se dirigem uns aos outros apenas pelo sobrenome. No treinamento de voluntários na Cotton Correctional, as autoridades penitenciárias incentivam a formalidade utilizando alcunhas e sobrenomes, mas deixam para o indivíduo decidir como gostaria de ser chamado. Neste workshop, os facilitadores utilizaram seus nomes, e a maioria dos homens no workshop se apresentou usando seus primeiros nomes ou apelidos de sua preferência. Isso, em si, cria uma comunidade diferente de muitas outras dentro das paredes da prisão. 
Como parte da metodologia do PCAP, os facilitadores participam das mesmas atividades artísticas que os participantes do workshop, em vez de assumir o papel de professores que se limitam a dar instruções. Neste workshop específico, a atividade introdutória utilizada foi "Meu nome é ...", uma chamada que estimulou os escritores a se apresentarem escrevendo sobre a origem de seu nome. Alguns escreveram sobre as pessoas de quem herdaram seu nome e a razão, juntamente com seus relacionamentos com seus homônimos. Outros escreveram sobre os significados bíblicos de seu nome ou escreveram seus nomes foneticamente, adicionando ritmo e estrutura dando a eles forma artística. Outros pegaram a raiz de seu nome e expuseram sobre elas. Aqui está o texto de apresentação escrito pelo participante Richard Strong:

Meu nome é Richard Anthony Strong e fui batizado em homenagem ao meu pai, um homem que não ligava para essa alcunha (Strong, em português, é "forte"). Mesmo considerando que ele não estava presente, ele ainda era meu ídolo. Quando ele morreu, foi a última vez que chorei. Eu deixei o ódio mudar meu destino, agora esse nome se tornou algo que me trouxe vergonha e algo para culpar. Esse nome tem aparecido em revistas, jornais e telas de TV, às vezes em prêmios, às vezes em coisas constrangedoras. Achei que vir para a prisão significava que meu nome estava acabado, mas continua vivo pois eu o passei para meu filho. ${ }^{9}$

Depois de estabelecer normas e metas para o workshop, e aprender mais sobre cada indivíduo, os facilitadores estabeleceram alguns rotinas dentro da agenda do workshop que se repetiram por todas as semanas, fornecendo alguma estrutura e enquadramento para a mudança de tarefas e tópicos discutidos. Uma dessas atividades, que acontecia no início de cada workshop era um exercício chamado "High Low" (Bons e Ruins). Raschid Zimmerman descreve esta atividade semanal aqui:

Depois que nos sentamos, cada um teria a sua vez de dar um "bom" e um "ruim" [...] Cada um de nós dizia o que achava bom. Depois dizíamos algo que achávamos ruim, ou explicaríamos algo que estava errado ou o que nos deixava triste. Por exemplo, por muitas vezes, a maioria de nós anunciava como estávamos felizes em nos vemos novamente e estar de volta ao workshop (ou qualquer outra coisa que estivesse acontecendo em nossas vidas que nos fizesse sentir bem), então expressávamos algo

${ }^{9}$ Richard Strong para Ashley Lucas, 22 de Julho, 2020. 
que poderia estar nos incomodando (não importava o que fosse), ou algo que poderia ter acontecido conosco ou com alguém importante em nossa vida. ${ }^{10}$

Conforme o workshop progredia, o compartilhamento desses baixos e altos, ou bons e maus momentos, ajudou a fortalecer a dinâmica do grupo, centrando a humanidade de cada indivíduo. Isso nos ajudou a compreender melhor uns aos outros e a sermos capazes de apoiar e elevar uns em momentos de necessidade e de felicidade. Esta e outras práticas criaram uma base sólida sobre a qual o workshop foi construído.

\section{Desenvolvimento do Workshop no Contexto do Cenário Político de Outono de 2017}

O workshop continuou a se desenvolver como um experimento sob medida especificamente para um esse grupo, oferecendo oportunidades de expressão por meio de poesia, prosa, jogos de teatroteatrais e discursos políticos. Aqui, o participante Steve Nicholson reflete sobre a rotina do workshop:

Para mim, um típico dia de workshop consiste em se preparar avidamente para o compartilhamento de ideias e a expansão das nossas próprias mentes [...]. Trabalhamos bem juntos. Pessoalmente, sempre gostei de começar com um jogo que sempre jogávamos enquanto o workshop esteve sobre os cuidados de Caroline, Ashley, Marena e Bryce [...]. Jogávamos partidas com temas de redação como "O que sou eu?" ou escrevendo sobre o que nossos nomes significavam e uma quantidade abundante de outras instruções que preenchiam o resto da hora. Às vezes, nos engajávamos em conversas cotidianas, provocadas por nossos textos e influenciados por problemas do mundo de fora, como a crise hídrica de Flint ou a eleição da governadora de Michigan [...]. Geralmente terminávamos com o jogo de "previsão" ou discutíamos como nos aprontar para a próxima semana. Contudo, a conexão humana foi um jeito incrível de se sentir normal novamente. ${ }^{11}$

Assim como Steve menciona em sua reflexão, as escritas e discussões

${ }^{10}$ Raschid Zimmerman para Ashley Lucas, 25 de Julho, 2020.

${ }^{11}$ Steven Nicholson para Ashley Lucas, 19 de Junho, 2020. 
ocorridas no workshop rapidamente começaram a adquirir um tom político. Questões do encarceramento, identidade política, pobreza e justiça social foram progredindo com as escritas sobre nomes, nossos altos e baixos e continuaram a surgir também em outros textos e improvisações. O outono de 2017 marcou um período político tenso. Este foi o primeiro ano da presidência de Donald Trump, antes que a maioria nos Estados Unidos pudesse se acostumar com a quebra perpétua de leis e precedentes de sua administração. O outono de 2017 também testemunhou a primeira onda do movimento \#MeToo, a introdução do "Fake News", o anúncio do Facebook de banir mais de 500 contas falsas de trolls russos, a marcha de supremacistas brancos em Charlottesville, North Carolina, que teve como estopim o plano de remover uma estátua dos Estados Confederados, o assassinato em massa de Las Vegas que matou 58 pessoas, a retirada dos Estados Unidos do Acordo de Paris, o furacão Maria atingindo Porto Rico e uma devastadora temporada de incêndios florestais na costa oeste americana. Os textos produzidos no workshop captaram ecos e reverberações de todos esses eventos e ofereceram oportunidades para todos os envolvidos compartilharem suas tristezas, angústias e indignações.

Algumas semanas após iniciarmos o workshop, os facilitadores planejaram uma apresentação de poesia falada em uma peça chamada "Somewhere in America" (Em Algum Lugar na América), escrita por Belissa Escobedo, Rhiannon McGavin e Zariya Allen, da organização GetLit, que notadamente participou na competição de poesia falada Brave New Voices 2014. O objetivo de incluir esta peça no workshop foi mostrar como os elementos do teatro e da performance impactam e como uma peça de escrita criativa é recebida pelos ouvintes. Este poema específico também exemplificou como combinar o pessoal e o político em um texto - uma habilidade que muitos no workshop esperavam desenvolver, dado o clima político peculiar da época.

Houve uma elevação dos ânimos depois que "Somewhere in America" foi apresentada para o grupo; foi um ponto de inflexão dentro do workshop - todas essas referências políticas e conversas paralelas que estavam se infiltrando entre vários aspectos da oficina de repente pareciam mais palpáveis, e prontas não 
apenas para serem expressas através de palavras e palavras escritas, mas compartilhadas através da performance também. Pouco depois, Richard Strong escreveu um texto intitulado "Justiça Poética" e o apresentou para o workshop. Aqui está um trecho:

Alguns dizem que o sistema está quebrado, mas eu acho que está funcionando bem

Aqueles que tem poder vivem livres, enquanto os oprimidos sacrificam o tempo.

É assim que foi concebido

Você fica derrubado por tanto tempo que sente que nunca vai se levantar. Oportunidade é rara em minha comunidade

Então, nos tornamos caranguejos em um mesmo tanque, desunidos.

Subeducados e manipulados a buscar nossa recompensa após a morte, Enquanto você vive sua vida ao máximo,

meu povo está oprimido.

Pré-adolescentes tomam pílulas porque dizem que estão estressados.

Mães negras choram por seus filhos mortos por policiais brancos

E elas ainda dizem que são abençoadas.

Nosso presidente não trata todos os americanos igualmente

Mas ele elogia os terroristas carregando tochas de fogo e os chama de "pessoas de bem". 12

Assim como esta obra, outros trabalhos começaram a surgir, explorando a conexão entre experiências pessoais e políticas, e o grupo coletivamente começou a expandir as formas como a escrita era executada dentro do workshop. A confiança foi construída entre o grupo à medida que a escrita se tornava cada vez mais vulnerável e os riscos de suas performances eram assumidos cada vez mais livremente. O tempo compartilhado entre eles foi inestimável e forneceu a afirmação e o incentivo que cada um precisava para continuar a evoluir como escritores e intérpretes.

\section{A Cultura de Compartilhamento a Caminho da Apresentação Final}

Nosso grupo desenvolveu uma profunda cultura de compartilhamento quando se tratava de nossa escrita. Após receber uma tarefa no workshop, cada

12 Richard Strong para Ashley Lucas, 22 de Julho, 2020. 
um de nós compartilhava o que escrevíamoescrevias, mesmo que fossem apenas algumas linhas não inspiradas. Adquirimos o hábito de encorajar uns aos outros, valorizando o trabalho de cada um e nos tirando de nossos momentos tímidos ou constrangidos. Muitas vezes, alguns de nós traziam obras em que estávamos trabalhando ao longo da semana e as compartilhávamos no início do workshop, buscando um incentivo ou parecer. Nossa escrita era profundamente pessoal, na medida em que refletia nossas emoções, crenças e experiências, e também inerentemente política, em que muitas de nossas experiências e crenças foram estruturadas pelas várias armadilhas de um contexto político em que cada um de nós, de formas distintas, sentíamos que nossa democracia não estava em nosso lado. O compartilhamento, colaboração e apoio coletivo permitiu que fosse criada uma arte mais significativa onde todos permaneciam imersos no trabalho que estávamos fazendo, e essas coisas estavam em nossas mentes quando começamos a pensar sobre nossa atuação final.

À medida que nosso workshop prosseguia, nosso senso de camaradagem e propósito comum cresciam a cada semana. O participante Steve Nicholson descreve a nossa comunidade do workshop:

Trabalhar com outros adultos sob custódia que eu não conhecia ou não me relacionava de uma forma mais profunda também foi revigorante. No final das contas, quase todos os homens da classe sentiram um senso de propósito mais forte de um jeito diferente ... Houve alguns homens que fizeram novas amizades e estabeleceram conexões, como no meu caso, em que ajudei um homem em sua dor com o vício contra o qual seu filho estava lutando seriamente ... Eu sempre conto aos meus entes queridos que este workshop é quase tão bom quanto quando eu recebo uma visita deles. Comecei a ansiar pelos workshops e os facilitadores como uma família. ${ }^{13}$

Como facilitadores, caminhamos sobre uma linha tênue entre respeitar os limites e regras da prisão e cultivar a harmonia da comunidade, que é a base do nosso trabalho. Toda a retórica do diretor de atividades especiais e funcionários promove a manutenção de barreiras entre nós, e que no fim, sempre nos lembram que temos que temer e desconfiar uns dos outros. Nosso trabalho cooperativo

\footnotetext{
13 Steven Nicholson para Ashley Lucas, 19 de Junho, 2020.
} 
como escritores teve o efeito oposto. Valorizamos a vulnerabilidade e a abertura, permitindo a consolidação de comunidades e níveis mais elevados de excelência artística em nossa obra compartilhada.

Todos os workshops do PCAP culminam em apresentações finais, geralmente com a presença de pessoas aprisionadas, alguns membros da comunidade do PCAP do mundo livre e funcionários da prisão que os supervisionam. Normalmente, os workshops de escrita criativa resultam na leitura pública dos textos individuais e os workshops de teatro apresentam energéticas cenas improvisadas. Havia uma competição saudável, mas forte entre os grupos de workshops do Cotton. O participante do workshop, Tyrone Reyes, descreve a cultura da competição, declarando:

Como éramos um grupo de escrita criativa, sabíamos que tínhamos que dar o nosso máximo. Estávamos nos apresentando ao lado de grupos de teatro que iam dar um show de verdade. ${ }^{14}$

Queríamos mostrar todo o trabalho criativo que estávamos fazendo, e muitas vezes brincávamos que era preciso dar de lavada em todos os outros grupos na noite da apresentação. Ficamos especialmente orgulhosos do profundo senso de comunidade e das discussões vitais que nosso workshop construiu. O participante Tyrone Reyes acrescenta:

Levar nossos facilitadores até a área dos guardas foi como ver nossa família saindo de uma visita. Não estávamos apenas participando de um workshop, éramos como uma família discutindo em torno da mesa. ${ }^{15}$

Por causa da orientação política de nosso grupo de workshop, foi uma decisão fácil ter os eventos atuais como o tema de nossa apresentação final. Em uma sessão em que debatermos ideias, veio o conceito de criar uma cena semelhante às coletivas de imprensa que assistíamos todos na TV, onde Sarah Huckabee Sanders era encarregada de defender todas as ações indefensáveis da

${ }^{14}$ Tyrone Reyes para Ashley Lucas, 22 de Maio, 2020.

15 Tyrone Reyes para Ashley Lucas, 22 de Maio, 2020. 
administração de Trump. Marena interpretaria Sarah Huckabee Sanders, e o resto de nós seríamos repórteres. Cada repórter faria uma pergunta, e essa pergunta seria a recitar um poema sobre determinado acontecimento recente. Cada um de nós elaborou nossos textos de forma independente, durante a semana, entre as sessões de workshop. Trouxemos nossos manuscritos para a classe e muitas vezes nos dividimos em pequenos grupos para ensaiar a execução e trocar opiniões para revisão. Durante a oficina, escrevemos linhas satíricas para Marena usar como resposta a cada apresentação e como transição para o tópico do próximo repórter. Praticamos o tempo e o fluxo de nossas apresentações, colocando-as em uma ordem que parecia coesa.

Ensaiamos por semanas, certificando-nos de que a ordem dos repórteres em nossa coletiva de imprensa fluísse impecavelmente e cada participante permanecesse no limite de tempo para que a equipe não interrompesse nossa apresentação quando o estrito limite de tempo se esgotasse. Muitos de nós nunca havia falado para uma grande audiência, muito menos compartilhando nosso próprio trabalho escrito. Nesse período, as apresentações finais no Cotton envolveram o convite a cerca de 200 homens da prisão e vinte voluntários do PCAP. Steve, um experiente escritor e artista, costumava dar o exemplo, encorajando outros a sair de sua zona de conforto: "Pessoalmente, gostei de ver outros homens na classe crescerem em suas [habilidades] com as palavras e sua confiança". ${ }^{16}$ Ainda assim, muitos de nós estávamos nervosos em nos expressar fora do conforto de nossa comunidade, abordando tais questões imediatas em um clima extremamente diviso, como em uma prisão.

Cada participante abordou um tópico proeminente qualquer por meio de sua escrita, escolhendo um assunto que carrega perto de seu coração e o apresentou como se fosse um repórter tentando entrevistar a secretária de imprensa. Tyrone escreve:

Escolher o meu tema foi fácil porque o movimento \#METOO estava em seu auge ... Eu queria que as pessoas na prisão prestassem atenção e parassem de ser abusadores [...] estou com nojo de mim mesmo, porque eu estou na prisão por não proteger uma garota, algo de que vou para

${ }^{16}$ Steven Nicholson para Ashley Lucas, 19 de Junho, 2020 
sempre me arrepender. Essa apresentação me deu a oportunidade de destacar o movimento \#METOO e como cabe a homens como eu combater os maus-tratos com nossas preciosas companheiras. Este workshop me ensinou que minha voz é necessária e que a maioria dos homens está disposta a escutar. ${ }^{17}$

Outros assuntos envolveram tópicos como o banimento da imigração de muçulmanos pela administração Trump (Bryce Vandenbelt), mudança climática (Ashley Munger) e o uso de trabalho não assalariado de prisioneiros para combater os incêndios florestais na Califórnia (Caroline Henderson). Richard Strong escreveu um artigo marcante intitulado "State of the Union" ("Estado da União") abordando a brutalidade policial contra afro-americanos:

Vamos falar a verdade, a liberdade deveria ser um direito dado por Deus, mas não é.

Devíamos ser livres para usar moletons com capuz, atravessar a rua, dirigir carros e não levar tiros da polícia [...]

Só porque minha pele é escura e não pálida, as chances de eu ser mandado para a prisão são maiores.

Se eu for pegar minha licença e você achar que é uma arma, serei assassinado na frente da minha filha ou filho?

Descanse em paz Trayvon Martin, Michael Brown e Philandro Castille: abatidos com suas mãos para cima ou mãos em cima do volante. ${ }^{18}$

Muitas vezes, nossos textos eram sobre questões nacionais; a única exceção foi David Hudson-Bey, cujo artigo local era sobre a crise hídrica em Flint. A crise hídrica em Flint foi uma catástrofe de saúde pública que devastou a cidade de Flint, Michigan. Como resultado das falhas em todos os níveis do governo, Flint foi transferida para um abastecimento de água que carecia de tratamento anticorrosivo e, como resultado, o chumbo dos canos antigos de distribuição de água contaminou a água potável em toda a cidade. O governo demorou a agir, mesmo considerando que a água contaminada pelo chumbo causa muitos problemas de saúde, alguns dos quais são permanentes - incluindo danos cerebrais em crianças. O povo de Flint ainda está lidando com as repercussões desta crise até hoje. O texto do David foi uma condenação do governo por falhar

17 Tyrone Reyes para Ashley Lucas, 22 de Maio, 2020.

${ }^{18}$ Richard Strong para Ashley Lucas, 4 de Junho de 2020. 
em responder adequadamente às necessidades de uma comunidade de maioria negra, que está passando por uma catástrofe ambiental e um apelo à ação em apoio ao povo de Flint.

Hudson-Bey, um experiente escritor, participante do PCAP e membro Associação Nacional de Prisioneiros Perpétuos de Cotton, era uma figura poderosa e reconfortante dentro de nosso grupo. Um homem alto em seus sessenta e poucos anos, Hudson-Bey sempre tinha um conhecimento para transmitir, um caloroso incentivo para compartilhar e uma piada para contar em nossa mesa de workshop. Nosso amigo David Hudson-Bey faleceu repentinamente no início de fevereiro de 2020 devido a um tumor no cérebro diagnosticado tardiamente, e nós sentimos muito sua falta. Seu colega Richard Strong escreveu: "David Hudson-Bey foi um soldado por mudança, um mentor, um líder, um amigo e nós vamos sentir muitas saudades dele". 19 Tyrone Reyes adicionou:

David Hudson-Bey, era o irmão mais velho de todos. Sua perda machucou muita gente, porque todos nós sabíamos o tanto que ele tinha a dar se tivesse outra chance de sair da prisão. Ele era um bom irmão, disposto a ajudar quando chamado [...] eu o ouvi e observei durante alguns de nossos eventos e admirei como ele foi capaz de manter o controle de uma sala. Sua contribuição foi inestimável em nosso grupo. ${ }^{20}$

Nos lembramos de seu riso e perspicácia, e esperamos que aqueles que o viram atuar em nosso workshop se lembrem de suas palavras veementes sobre a injustiça em Flint.

\section{Atuação Final e um Novo Tipo de Comunhão}

Na noite de nossa apresentação final, os facilitadores chegaram ao Cotton uma hora mais cedo, junto com 15 ou 20 outros membros do PCAP, incluindo facilitadores de outras oficinas realizadas no Cotton naquele semestre. Em um dia bom, passar pela segurança já leva em média 20 minutos, e a aglomeração de

${ }^{19}$ Richard Strong para Ashley Lucas, 16 de Junho, 2020.

20 Tyrone Reyes para Ashley Lucas, 22 de Maio, 2020. 
pessoas adicionais tornou o processo consideravelmente mais demorado. Quando todos do mundo de fora chegaram ao ginásio de Cotton, faltavam apenas alguns minutos para o início do evento. Mais de 100 dos homens encarcerados em Cotton estavam presentes nas arquibancadas, esperando o início do show.

A programação foi definida. Deveríamos ser os terceiros, sendo precedidos pelo workshop de música e um dos workshops de teatro e sucedidos pelo segundo workshop de teatro. Nosso grupo sentou-se em cadeiras dobráveis na beira do ginásio, esperando pela nossa vez. Embora estivéssemos ansiosos, tudo deu certo quando chegou a hora. Com nossas cadeiras arranjadas em fileiras voltadas para um púlpito complementando o cenário de nossa entrevista coletiva, entregamos, poema após poema, a crítica política exatamente da maneira como tínhamos praticado.

Nossa apresentação naquela noite foi muitas coisas; foi engraçada e sombria, foi alegre e cheia de tristeza, foi uma representação da realidade e uma apresentação obviamente montada com os recursos limitados da prisão. Acima de tudo, era solidariedade e união. O público riu enquanto o personagem de Marena se atrapalhava tentando escapar de cada tópico, dizendo coisas como "Chega de encarceramento, vamos falar sobre o ótimo trabalho que a administração fez para parar os incêndios florestais na Califórnia" antes do poema de Caroline sobre a resposta inadequada aos incêndios e o perigo colocado para as pessoas encarceradas que lutam contra eles na Califórnia. Quando cada novo repórter se levantava para recitar sua pergunta para Marena, que era feita na forma de poema sobre um determinado assunto, o público batia palmas e dava gritos de anuência com as críticas expressas em cada atuaçāo. Não foi uma competição, mas nos sentimos vencedores.

A adrenalina da apresentação foi seguida pela sóbria percepção de que os facilitadores teriam que ir embora. Nosso workshop acabou. Não sabíamos se ou quando nos veríamos novamente, dada a incerteza natural que vem com as relocações na prisão e planos de pós-graduação. Não podíamos nos abraçar, então apertamos as mãos, agradecendo e desejando boa sorte uns aos outros, de uma maneira que nunca poderíamos resumir como estávamos nos sentindo. Embora 
nosso futuro fosse incerto, todos conhecíamos a força do que havíamos feito naquela noite. O companheirismo nem sempre é uma coisa fácil de acontecer, e nós o criamos e nutrimos nas condições mais adversas. Falamos juntos em resistência às coisas que nos prende, nos impedem e nos separam. No contexto frio e desanexado da prisão, nos reunimos e trouxemos outras pessoas conosco para que todos saibam que rejeitamos a injustiça e as estruturas que nos confinam - todos nós.

Hoje, enfrentamos muitos dos mesmos obstáculos e dilemas políticos que vivemos no outono de 2017. Muitos de nós permanecemos presos e continuamos a lutar diariamente para sustentar nossa dignidade humana e direitos básicos. A brutalidade policial e os assassinatos continuam a ocorrer, apesar dos protestos em massa e dos apelos por reforma e abolição. Desde o início deste projeto, vimos a vida de vários afro-americanos ser violentamente encerradas por policiais e grupos de supremacia branca, incluindo as vidas de Breonna Taylor, George Floyd, Rayshard Brooks e Ahmaud Arbery. Na verdade, a polícia matou pelo menos um homem ou mulher negra nos Estados Unidos todas as semanas em 2020. ${ }^{21}$ Além disso, ao longo dos últimos meses, vimos um ressurgimento de devastadores incêndios florestais ao longo da costa oeste dos EUA e o uso de pessoas encarceradas para lutar contra essas chamas imensas e assoladoras, lembrandonos mais uma vez da força de trabalho não remunerada ou grosseiramente mal paga composta de americanos presos. Claro, as falhas da presidência de Trump também se ampliaram, incluindo uma resposta à pandemia internacional do COVID-19 que deixou os Estados Unidos com o maior número de casos confirmados e mais mortes pelo vírus do que qualquer outra nação do mundo. ${ }^{22}$

Muitos de nós, talvez idealisticamente, esperávamos que o ativismo que inspirou nossa atuação no outono de 2017 enraizasse e tornasse a mudança e o progresso possíveis nos próximos anos. Ao nos comunicarmos mais uma vez para

${ }^{21}$ Police in the U.S. killed 164 Black people in the first 8 months of 2020, CBS News. Acesso em: 13 out. 2020 , https://www.cbsnews.com/pictures/black-people-killed-by-police-in-the-u-s-in-2020/

22 "The U.S. has more coronavirus cases than some countries have people," Caitlin O'Kane, CBS News. Acesso em: 13 out. 2020, https://www.cbsnews.com/news/coronavirus-usa-more-covid-cases-countries-people/ 
este projeto, vemos que nossa apresentação de três anos atrás poderia facilmente ter sido escrita e executada hoje. Steve Nicholson escreve:

A política na época da nossa performance está ainda mais relevante neste momento. Ainda mais que antes. Se este país realmente deseja ver mudanças, nossa fundação básica precisa mudar ... e parte disso é a forma como punimos as pessoas que infringem as leis. ${ }^{23}$

A relevância contínua de nossa apresentação de 2017 é decepcionante em muitos aspectos, pois não era para ser um trabalho atemporal. No entanto, desapontamento é um sentimento ao qual você se acostuma quando está preso e quando você é alguém que se preocupa com pessoas encarceradas. A decepção certamente ocupou muito de nossos pensamentos, pois o COVID-19 não só impediu a continuação das oficinas presenciais do PCAP, junto com todas as outras programações e visitas presenciais da prisão, mas também matou de forma devastadora milhares de pessoas encarceradas, como tem acontecido com uma força desenfreada e em grande parte não contida nas prisões americanas. ${ }^{24}$

No entanto, por meio de nossa decepção e tristeza, nos unimos mais uma vez, enviando cartas escritas à mão pelo correio, lembrando-nos um ao outro do poder de nossas vozes criativas. E, mais uma vez, vamos resistindo de formas aparentemente pequenas, mas subversivas. Somos um coletivo de escritores que sempre estaremos prontos para desafios de nossos tempos e criaremos juntos coisas além das que são esperadas.

Em 2017, Steve Nicholson encerrou nossa apresentação com um texto expressivo e potente que parecia conter e transcender nossos medos e intenções coletivas. Este trecho final exibe sua inclusão expansiva ao passado, presente e futuro, e nos alenta a procurar continuamente a coragem dentro de nós mesmos, para buscar paz e justiça, mesmo em meio aos tempos mais desastrosos:

${ }^{23}$ Steven Nicholson para Ashley Lucas, 19 de Junho, 2020.

24 "A state-by-state look at coronavirus in prisons," The Marshall Project. Acesso em: 13 out. 2020, https://www.themarshallproject.org/2020/05/01/a-state-by-state-look-at-coronavirus-in-prisons 


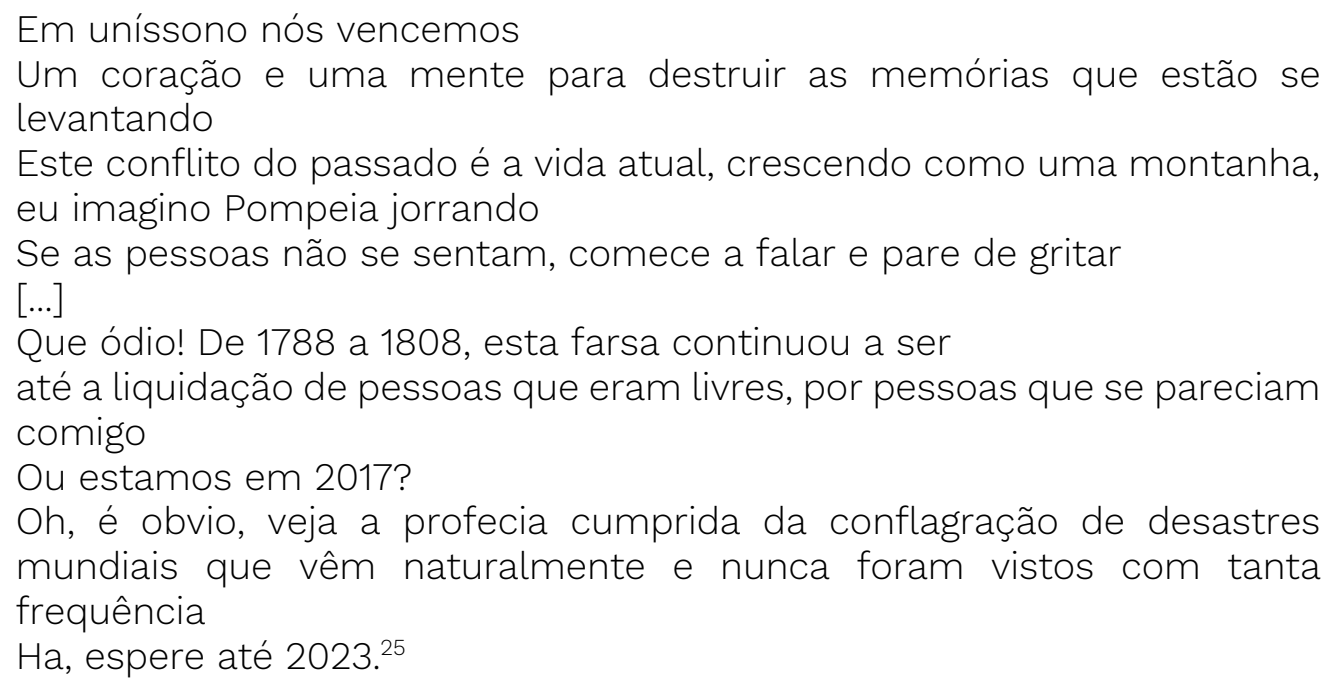

\section{Referencias}

CBS News. "Police in the U.S. Killed 164 Black People in the First 8 Months of 2020. These Are Their Names. (Part I: January-April)." CBS Interactive, September 10, 2020. https://www.cbsnews.com/pictures/black-people-killed-by-police-inthe-u-s-in-2020/.

The Marshall Project. "A State-by-State Look at Coronavirus in Prisons." The Marshall Project, October 12, 2020.

https://www.themarshallproject.org/2020/05/01/a-state-by-state-look-atcoronavirus-in-prisons.

NICHOLSON, Steven. Steven Nicholson to Ashley Lucas, June 19, 2020. Letter.

O'KANE, Caitlin. "The U.S. Has Had More Coronavirus Cases than Some Countries Have People." CBS Interactive, August 10, 2020. https://www.cbsnews .com/news/coronavirus-usa-more-covid-cases-countries-people/.

REYES, Tyrone. Tyrone Reyes to Ashley Lucas, May 22, 2020. Letter.

STRONG, Richard. Richard Strong to Ashley Lucas, June 4, 2020. Letter.

STRONG, Richard. Richard Strong to Ashley Lucas, June 16, 2020. Letter.

STRONG, Richard. Richard Strong to Ashley Lucas, July 22, 2020. Letter.

${ }^{25}$ Steven Nicholson para Ashley Lucas, 19 de Junho, 2020. 
ZIMMERMAN, Raschid. Raschid Zimmerman to Ashley Lucas, July 25, 2020. Letter.

Recebido em: 30/10/2020

Aprovado em: 02/12/2020

Universidade do Estado de Santa Catarina - UDESC

Programa de Pós-Graduação em Teatro - PPGT

Centro de Arte - CEART

Urdimento - Revista de Estudos em Artes Cênicas

Urdimento.ceart@udesc.br 